\title{
The effect of high-molecular-weight guar gum on net apparent glucose absorption and net apparent insulin and gastric inhibitory polypeptide production in the growing pig: relationship to rheological changes in jejunal digesta
}

\author{
BY P. R. ELLIS ${ }^{1 *}$, F. G. ROBERTS ${ }^{1,2}$, A. G. LOW' AND L. M. MORGAN ${ }^{3}$ \\ ${ }^{1}$ Biopolymers Group, Division of Life Sciences, King's College London, Campden Hill Road, \\ Kensington, London W8 7 AH \\ ${ }^{2} A F R C$ Institute for Grassland and Environmental Research, Shinfield, Reading RG2 9AQ \\ ${ }^{3}$ Nutritional Metabolism Research Group, School of Biological Sciences, University of Surrey, \\ Guildford GU2 $5 X H$
}

(Received 31 October 1994 - Accepted 10 February 1995)

\begin{abstract}
The present study was designed to determine the quantitative effects of starchy meals containing guar gum on rates of net apparent glucose absorption and net apparent insulin and gastric inhibitory polypeptide (GIP) production in growing pigs. The effects of these meals on the viscosity of jejunal digesta were also examined and correlated to changes in glucose absorption. Four growing pigs were each given either a low-fat semi-purified diet (control) or the same diet supplemented with a high-molecularweight guar gum at concentrations in the diet of 20 or $40 \mathrm{~g} / \mathrm{kg}$. Blood samples were removed simultaneously via indwelling catheters from the mesenteric artery and the hepatic portal vein. Samples of jejunal digesta were removed via a T-piece cannula and used immediately for viscosity measurements at $39^{\circ}$. The 'zero-shear' viscosity of each sample was then calculated. Blood-flow measurements were made using an ultrasonic flow probe fitted to the hepatic portal vein. All measurements were made at intervals of 10 or 30 min during a $4 \mathrm{~h}$ postprandial period. Meals containing guar gum significantly increased $(P<0.05)$ the viscosity of jejunal digesta, an effect that was strongly dependent on the concentration of guar gum in the original diet. No significant differences in blood-flow rates were found between the control and guar-containing diets. Both concentrations of guar gum significantly reduced $(P<0.05)$ glucose absorption and insulin and GIP secretion rates over the 4 h postprandial period. An inverse relationship between the rate of glucose absorption and the 'zero-shear' viscosity of jejunal digesta was found. This study also provides direct evidence for the important role played by the enteroinsular axis in modifying the glycaemic response to a meal containing guar gum.
\end{abstract}

Guar gum: Nutrient absorption: Viscosity: Pig

It is now well established that the addition of soluble non-starch polysaccharides (s-NSP), such as guar gum and pectin, to oral carbohydrate loads reduces postprandial blood glucose and plasma insulin levels. This has been observed in human subjects (Jenkins $e t$ al. 1978; Ellis et al. 1981; Jarjis et al. 1984) and experimental animal models such as the pig (Sambrook \& Rainbird, 1985). Insulin is known to play a key role in the carbohydrate and lipid metabolism of man. The modification of insulin secretion by s-NSP may have

* For reprints. 
important implications, therefore, for our understanding of the aetiology of diseases such as diabetes mellitus and atherosclerosis (Morgan et al. 1988). The beneficial effects of s-NSP on carbohydrate tolerance and lipid metabolism (i.e. reductions in plasma LDL-cholesterol) have important clinical applications, notably in the management of diabetes (Peterson et al. 1987).

Guar gum, an endosperm extract of the Indian cluster bean (Cyamopsis tetragonoloba (L.) Taub.), is frequently used as a 'model' polysaccharide in physiological and nutritional studies for a number of reasons. First, it can be isolated as a relatively pure form of s-NSP, consisting mainly of a high-molecular-weight galactomannan. Second, its physico-chemical properties have been well defined (Ellis \& Morris, 1991) and can be easily modified, e.g. depolymerization of the galactomannan fraction (Robinson et al. 1982; Ellis et al. 1986).

The physiological mechanisms by which s-NSP improve carbohydrate tolerance and lipid metabolism are, as yet, incompletely understood. The postprandial effects of guar gum appear to depend on its capacity to increase the viscosity of digesta within the gastrointestinal tract, by the entanglement of fully hydrated chains of galactomannan. This in turn is thought to reduce the rate of digestion and absorption of carbohydrate and therefore attenuate the postprandial rise in blood glucose (Blackburn et al. 1984; Edwards \& Read, 1990). However, there have been few studies on the relationship between the rheological properties of guar gum in vivo and subsequent postprandial changes in blood glucose and plasma hormone concentrations. This is due, in part, to the difficulty of measuring viscosity in vivo (Ellis et al. 1986). Preliminary studies in pigs given guarcontaining meals indicated that maximum levels of digesta viscosity in the mid-jejunum (Roberts et al. $1990 a, b$ ) seem to correspond with reductions in postprandial hyperglycaemia and plasma insulin levels seen in pigs (Sambrook \& Rainbird, 1985) and human subjects (Jenkins et al. 1978; Morgan et al. 1985; Ellis et al. 1991). The reduction in postprandial insulin concentration is also attributed to a diminished stimulation of the entero-insular axis, notably the insulinotrophic gut hormone gastric inhibitory polypeptide (GIP; Morgan et al. 1979, 1985). The secretion of GIP is directly related to the rate and site of glucose absorption.

Although it is frequently stated that guar gum delays the rate of absorption of glucose and other nutrients (Jenkins et al. 1978), the evidence to substantiate this view has been obtained indirectly. Thus, in carbohydrate tolerance tests using human subjects, postprandial plasma glucose and insulin levels are normally determined at discrete time intervals on blood samples taken from the peripheral circulation (Ellis et al. 1991; Gatenby et al. 1991). However, measurements of glucose in the peripheral blood do not provide an accurate and direct quantitative index of the rate and degree of absorption of glucose. Nevertheless, some useful indirect measurements have been provided by both in vitro (Macagno et al. 1982; Edwards et al. 1988) and in vivo (Rainbird et al. 1984) modelling systems. A more reliable and direct quantitative method, using the pig as an animal model for man, is to measure the differences in glucose levels between the hepatic portal vein and the mesenteric artery, and, simultaneously, the flow rate of the portal blood (Rérat et al. $1977,1979,1988$ ). Numerous methods are available for the measurement of blood-flow rate (e.g. thermal, dye and isotope dilution) and in earlier studies an electromagnetic blood-flow probe was used; however, the recent development of ultrasonic flow probes has enabled long-term measurements to be made on vessels which collapse or vary in diameter, such as veins (Barnes et al. 1983).

The present study was designed, therefore, to determine the quantitative effects of a wellcharacterized form of guar gum on rates of apparent glucose absorption and apparent insulin and GIP production. In addition, the viscosity of digesta collected from the small intestine of growing pigs was measured and correlated to changes in glucose absorption. 
Accordingly, the pigs were surgically modified by the insertion of two indwelling catheters in the hepatic portal vein and the mesenteric artery and an ultrasonic blood-flow probe was attached to the hepatic portal vein to measure instantaneous blood-flow rate. The pigs were also fitted with a simple $T$-piece cannula, located in the mid-jejunum, to allow removal of digesta samples for subsequent viscosity determinations.

\section{MATERIALS AND METHODS \\ Animals and housing}

Four Large White $\times$ Landrace boar pigs initially of $35 \mathrm{~kg}$ live weight were used. The animals were kept in a single room but housed individually in metabolism crates, with a floor area of $1.8 \mathrm{~m}^{2}$, and kept at a constant temperature of $20 \pm 1^{\circ}$.

\section{Surgical modifications}

Each pig was prepared with two indwelling catheters, one in the hepatic portal vein and a second in the mesenteric artery. The animals were also fitted with a $12 \mathrm{~mm}$ Transonic ${ }^{(8)}$ blood-flow probe (Transonic Systems Ltd, Ithaca, NY, USA). The probe was attached to the hepatic portal vein as close to the catheter site as was possible without interfering with blood-flow measurements. The probe flex was exteriorized through the body wall on the left flank slightly below the catheters. Both the probe flex and catheter tubing were held in place with elastic bandage. Finally, a simple T-piece cannula of the type described by Rainbird (1983) was fitted in the mid-jejunum of each pig, $2.0 \mathrm{~m}$ distal to the pylorus of the stomach. The insertion of the catheters and the blood-flow probe was carried out according to the basic surgical details described earlier by Rérat et al. (1980). The animals were kept in dorsal recumbency and all modifications were carried out through a mid-line incision extending from xiphisternum to prepuce.

\section{Post-operative care}

The catheters were flushed daily with a solution of heparinized physiological saline ( $50 \mathrm{IU} / \mathrm{ml}$ in a $9 \mathrm{~g} \mathrm{NaCl} / 1$ solution). The area around the exit site for the probes and catheters was carefully washed and dried and sulphanilamide powder applied. Bandages were changed every 3-4 d and the sutures removed after $7 \mathrm{~d}$. The area around the cannula was washed daily with a weak veterinary antiseptic solution and a water-resistant barrier cream (Sudocrem, Tosara Products (UK) Ltd, Liverpool, Merseyside) applied to the surrounding skin. Attention to post-operative care was of great importance because of the complexity of the surgical procedures involved.

\section{Diet composition}

The animals received a control basal, low-fat, semi-purified (SP) diet based on wheat starch and casein, fed wet on a $1: 2.5 \mathrm{w} / \mathrm{v}$ basis. The composition of the diet is presented in Table 1 .

\section{Guar gum}

Guar-gum flour (Meyprogat 150 flour; Meyhall Chemicals (UK) Ltd, Wirral, Merseyside), consisting mainly of high-molecular weight $\left(\mathrm{M}_{\mathrm{w}}\right)$ galactomannan (about $847 \mathrm{~g} / \mathrm{kg}$ guar gum), was incorporated into the control SP diet at concentrations of 20 or $40 \mathrm{~g} / \mathrm{kg}$. The guar gum was added to the SP diet as an aqueous solution by dispersing it in tap water (e.g. 2.5 litres for a $50 \mathrm{~kg}$ pig receiving $1 \mathrm{~kg} \mathrm{SP}$ diet/feed) for $12 \mathrm{~h}$ to allow it to hydrate as fully 
Table 1. Composition of the experimental diet $(\mathrm{g} / \mathrm{kg})$

\begin{tabular}{lr}
\hline Ingredients & $\mathrm{g} / \mathrm{kg}$ \\
\hline Wheat starch & $680 \cdot 9$ \\
Maize oil & $30 \cdot 0$ \\
Casein & $180 \cdot 0$ \\
Solka floc & $60 \cdot 0$ \\
Trace mineral mix ${ }^{*}$ & $10 \cdot 0$ \\
Vitamin mix $\dagger$ & $2 \cdot 0$ \\
Dicalcium phosphate & $31 \cdot 0$ \\
Choline hydrochloride & $1 \cdot 1$ \\
Sodium chloride & $5 \cdot 0$ \\
Total B-group vitamins $(\mathrm{mg})$ & $30 \cdot 0$ \\
\hline
\end{tabular}

* Supplied (/kg diet) $: \mathrm{K}_{2} \mathrm{CO}_{3} 4.47 \mathrm{~g}, \mathrm{MgCO}_{3} . \mathrm{H}_{2} \mathrm{O} 1.73 \mathrm{~g}, \mathrm{FeSO}_{2} .7 \mathrm{H}_{2} \mathrm{O} 0.33 \mathrm{~g}, \mathrm{MnSO}_{4} .4 \mathrm{H}_{2} \mathrm{O} 80 \mathrm{mg}, \mathrm{ZnCO}_{3}$ $0 \cdot 10 \mathrm{~g}, \mathrm{NaF} 8 \mathrm{mg}, \mathrm{CuSO}_{4} .5 \mathrm{H}_{2} \mathrm{O} 17 \cdot 5 \mathrm{mg}, \mathrm{CoCl}_{2} 6 \mathrm{mg}$.

$\dagger$ Supplied (/kg diet) : retinol $12.5 \mathrm{mg}$, cholecalciferol $0.6 \mathrm{mg}$, riboflavin $3.25 \mathrm{mg}$, thiamin $2.0 \mathrm{mg}$, nicotinic acid $15.75 \mathrm{mg}$, pantothenic acid $16.0 \mathrm{mg}$, pyridoxine $3.25 \mathrm{mg}$, DL- $\alpha$-tocopherol acetate $4.0 \mathrm{mg}$, biotin $5.0 \mathrm{mg}$, pteroylmonoglutamic acid $1.0 \mathrm{mg}, \tau$-inositol $195 \mathrm{mg}$, ascorbic acid $30.0 \mathrm{mg}$, menadione $2.0 \mathrm{mg}, p$-aminobenzoic acid $20 \cdot 0 \mathrm{mg}$.

as possible. This resulted in guar-gum concentrations in the diet equivalent to 8 and $16 \mathrm{~g}$ guar gum $/ 1$ solutions respectively. Each solution was then mixed $(5 \mathrm{~min})$ with the control diet $15 \mathrm{~min}$ before feeding. A Kenwood hand blender was used to homogenize the feed.

\section{Animal weighing and feeding}

The animals were weighed every $7 \mathrm{~d}$ and fed on a scale based on $40 \mathrm{~g} / \mathrm{kg}$ body weight per d (e.g. $2 \mathrm{~kg} \mathrm{SP} \mathrm{diet/d} \mathrm{for} \mathrm{a} 50 \mathrm{~kg} \mathrm{pig}$ ). Food was offered twice daily in equal meals (by weight) at 08.00 and 16.00 hours. Before the onset of the first treatment period all animals had been conditioned to eat each feed within $10 \mathrm{~min}$; this was done to minimize variations in the time course of nutrient absorption. Each pig received each of the three diets for a week. The diets were allocated on a random basis and were changed on the Thursday evening of each week to allow $3 \mathrm{~d}$ adaptation before sampling.

\section{Blood and digesta sampling}

Blood sampling. After $3 \mathrm{~d}$ adaptation to the diet, blood samples were taken on the 4 th and 7 th day of each of the control and guar-gum diet periods. Sampling was carried out on conscious, unrestrained animals at the following times: -10 and $0 \mathrm{~min}$, then at $10,20,30$, 40,50 and $60 \mathrm{~min}$ after the start of the morning feed and then at $30 \mathrm{~min}$ intervals up to $4 \mathrm{~h}$ post-feeding. A $6 \mathrm{ml}$ blood sample was removed from each catheter and immediately centrifuged for $15 \mathrm{~min}$ at $9000 \mathrm{~g}$. A $2 \mathrm{ml}$ sample of plasma was used for subsequent insulin and GIP assays. A further $2 \mathrm{ml}$ of plasma was deproteinized (using $2 \mathrm{ml} 10 \mathrm{~g}$ trichloroacetic acid/1, BDH Chemicals Ltd, Poole, Dorset) overnight at $4^{\circ}$, centrifuged at $9000 \mathrm{~g}$ for 15 min and the supernatant fraction used for glucose analysis.

Blood-flow recordings. Continuous pre- and postprandial portal blood-flow-rate measurements were made on the days of blood sampling. The ultrasonic blood flow probe located in the pig was linked directly to a recorder (Transonic Systems Ltd) which automatically produced a value for integrated flow rate.

Digesta sampling and viscosity measurements. Digesta samples $(10 \mathrm{ml})$ were taken from the jejunal cannula at -10 and $0 \mathrm{~min}$ and then at 10,20,30,40,50 and $60 \mathrm{~min}$ followed by intervals of $30 \mathrm{~min}$ up to $4 \mathrm{~h}$ post-feeding. The 'zero-shear' viscosity of each sample was 
determined immediately (Morris, 1990). 'Zero-shear' viscosities of guar-gum solutions (8 and $16 \mathrm{~g}$ guar gum/1) were also measured before they were added to SP diets. A Brookfield DV-II rotoviscometer (Brookfield Instrumentation, Stoughton, MA, USA) fitted with a small-sample adaptor was used. A full description of maximum 'zero-shear' viscosity and shear-thinning behaviour of reasonably polydisperse random-coil polysaccharides at concentrations above the onset of coil-overlap and entanglement (the so-called $c^{*}$; Robinson et al. 1982) can be characterized by using equation 1:

$$
\eta=\eta_{0} /\left(1+\left(\dot{\gamma} / \dot{\gamma}_{\frac{1}{2}}\right)^{\mathbf{0} \cdot 76}\right)
$$

where $\eta$ at any shear rate $(\dot{\gamma})$ can be characterized by two variables: the maximum 'zero shear' viscosity $\left(\eta_{0}\right)$ and the shear rate $\left(\dot{\gamma}_{\frac{1}{2}}\right)$ at which viscosity is reduced to $\eta_{0} / 2$. The values of $\eta_{0}$ and $\dot{\gamma}_{\frac{1}{2}}$ can be derived from, respectively, the intercept and the slope of a simple linear plot of $\eta v . \eta \dot{\gamma}^{0.76}$ (Morris, 1990). Viscosity measurements were taken at $39^{\circ}$ within $60-90 \mathrm{~s}$ of removal of the digesta samples from the animal. In contrast to earlier studies (Roberts et $a l .1990 a, b)$ the sample could not then be returned to the small intestine because the animals were fitted with T-piece as opposed to re-entrant cannulas. This resulted in a total loss of sample of approximately $120 \mathrm{ml}$ over the whole sampling period. This amount (less than $3 \%$ of the total flow volume) is unlikely to produce a feedback effect on gastric emptying.

\section{Biochemical assays}

Glucose. Plasma glucose in the deproteinized samples was determined using a glucose oxidase-peroxidase (EC 1.11.1.7) procedure (Boehringer Mannheim, Mannheim, Germany) with a fully automated system ('Encore' Baker Instruments Corp., Pennsylvania 18001, USA).

Insulin. A double-antibody radioimmunoassay procedure was used (kit method supplied by Guildhay Antisera, Guildford, Surrey). The plasma sample was initially incubated with the primary reagents, i.e. assay buffer, insulin antiserum, normal guinea-pig serum, test plasma and ${ }^{125}$ I-labelled insulin (Amersham International, Amersham, Bucks) for 16-24 h. This was followed by a $2 \mathrm{~h}$ phase separation with polyethyleneglycol (PEG)-accelerated second antibody (BDH Chemicals Ltd). After the final spin and aspiration, the remaining pellets were counted on an Inter-Technique CG 4000 gamma sample counter.

Gastric inhibitory polypeptide. A double-antibody radioimmunoassay procedure was used for the determination of GIP (Morgan et al. 1979), using an antiserum directed against porcine GIP and porcine-GIP standards. The main procedure of the assay involved a $48 \mathrm{~h}$ incubation of primary reagents and sample, followed by a phase separation with PEGaccelerated second antibody.

\section{Calculation of glucose absorption and hormone secretion}

Glucose absorption and apparent insulin and GIP production were calculated from veno-arterial differences in the mesenteric artery and hepatic portal vein, and portal bloodflow rate determinations. Insulin and GIP concentrations can only be described as 'apparent' due to the pulsatile secretion and hepatic extraction effects in the former and variable half-life values for both. Calculations were done by using equations (2) and (3) from the method of Rérat et al. (1980):

$$
\begin{gathered}
q=\left(C_{p}-C_{a}\right) F(\mathrm{~d} t), \\
Q=q \sum_{t_{0}}^{t_{1}},
\end{gathered}
$$

where $q$ is the quantity of glucose absorbed or hormone produced during the short time 
(e.g. $\mathrm{d} t, 10 \mathrm{~min}$ ) during which each factor was considered to be constant; $C_{p}$ is the portal concentration; $C_{a}$ is the arterial concentration; $F$ is the instantaneous blood-flow rate; and $Q$ is the quantity of glucose absorbed or hormone produced during the postprandial period between times $t_{0}$ and $t_{1}$.

\section{Statistical analysis}

Control and guar-gum diets were allocated to each pig in a repeated measures design; each pig received each diet twice, giving a measure of within- and between-pig variation. Repeated measures ANOVA was used to make comparisons between control and guargum diets for 'zero-shear' viscosity, portal blood-flow rates and plasma glucose, insulin and GIP. Analysis was carried out on values for postprandial concentrations, time to reach peak value and glucose absorption and hormone production. The statistical programme used throughout was GENSTAT V (Rothamsted Experimental Station, 1989). Correlation analysis was done to determine the relationship between glucose absorption and 'zeroshear' viscosity of digesta, and also between glucose absorption and the production of either insulin or GIP. Statistically significant differences were accepted at $P<0.05$.

\section{RESULTS}

In general, no practical difficulties were experienced in ensuring that the pigs ate the appropriate quantities of diet containing 20 or $40 \mathrm{~g}$ guar gum $/ \mathrm{kg}$. All the diets were palatable to the pigs and there were no significant differences in the time taken to eat each diet (mean value 8 (SEM 1.5) min). All results are presented as mean values $(n 8)$.

\section{'Zero-shear' viscosity of digesta}

Postprandial changes in 'zero-shear' viscosity of the jejunal digesta over $4 \mathrm{~h}$ in response to control or guar-gum diets are presented in Fig. 1 and Table 2. Table 2 also includes 'zeroshear' viscosity values of guar-gum solutions and information about statistical differences. The viscosity of jejunal digesta was significantly increased $(P<0.05)$ in pigs given SP diets containing high $\mathbf{M}_{\mathrm{w}}$ guar gum and this was strongly dependent on the concentration of guar gum in the original diet (Table 2). However, the differences in digesta viscosity between the two concentrations of guar gum were significantly smaller than the difference in viscosity between the corresponding concentrations of guar gum in solution. Peak postprandial viscosity after each of the guar-gum treatments was reached within $1 \mathrm{~h}$, although the time to reach a peak value after the meal containing $40 \mathrm{~g}$ guar gum $/ \mathrm{kg}$ was approximately 20 min later than that seen after the $20 \mathrm{~g}$ guar gum $/ \mathrm{kg}$ meal (Table 2 ).

\section{Portal blood-flow rates}

The addition of guar gum to the diet had no significant effect on blood-flow rate at any point up to $4 \mathrm{~h}$ postprandially (Fig. 2). After each diet there was a slight increase in blood flow following the morning feed. This was quickly followed by establishment of a steadystate blood-flow rate (pooled mean of all animals) of 1.36 (SEM 0.30) litres/min or $38.8 \mathrm{ml} / \mathrm{min}$ per $\mathrm{kg}$ live weight, which was slightly higher than initial pre-feeding values.

\section{Postprandial changes in blood glucose, insulin and GIP concentrations}

At each sampling time point during the $4 \mathrm{~h}$ postprandial period the effects of control and guar-gum diets on plasma glucose and hormone concentrations were determined in both the portal and arterial blood (Fig. 3). Diets containing guar gum consistently produced significant reductions $(P<0.05)$ in plasma glucose, GIP and, to a lesser extent, insulin 


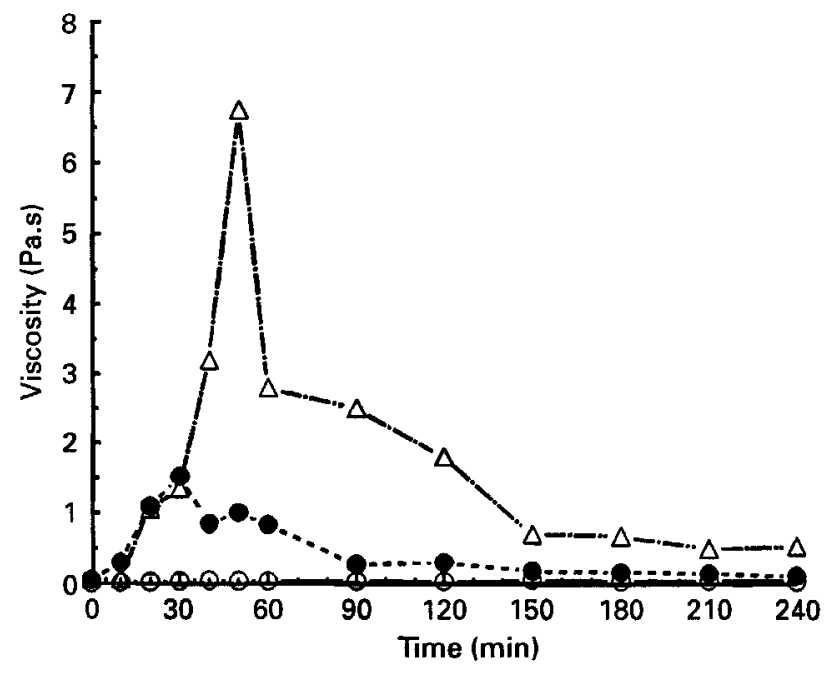

Fig. 1. Effect of guar-gum supplementation on 'zero-shear' viscosity of digesta from the mid-jejunum of growing pigs: (O) control semi-purified (SP) diet; (O) SP diet supplemented with $20 \mathrm{~g}$ guar gum $/ \mathrm{kg}$; $(\triangle)$ SP diet supplemented with $40 \mathrm{~g}$ guar gum $/ \mathrm{kg}$. Values are means for four pigs. For SED and statistical differences see Table 2. For details of composition of SP diet see Table 1 .

concentrations in the portal blood compared with the control. The magnitude of each response was dependent on the concentration of guar gum in the diet. The glucose- and insulin-lowering properties of guar gum were greatest during the first $30-40 \mathrm{~min}$ postprandially, although significant reductions in glucose level were sustained throughout the entire postprandial sampling period. Only the highest concentration of guar gum $(40 \mathrm{~g} / \mathrm{kg})$ significantly reduced plasma insulin levels at some of the later postprandial times $(150-210 \mathrm{~min})$. The $20 \mathrm{~g} / \mathrm{kg}$ guar gum diet had little or no insulin-lowering effect at the later postprandial times. Following an initial rise to a peak value in the first hour, GIP concentrations in the portal blood in response to all the diets remained, more or less, at a plateau until $150 \mathrm{~min}$, at which point there was a slight but steady decline. The presence of guar gum in the diet produced a significant $(P<0.05)$ attenuation of the GIP response throughout the $4 \mathrm{~h}$ sampling period, although no reductions were seen after the lowest concentration of guar gum in the first $30 \mathrm{~min}$ postprandially.

The effects of guar gum on arterial concentrations of glucose, insulin and GIP at each time point were often less marked than for the corresponding portal values. Nevertheless, in response to the diet containing the highest concentration of guar gum $(40 \mathrm{~g} / \mathrm{kg})$ there were significant reductions $(P<0.05)$ in glucose, insulin and GIP concentrations in arterial blood at most of the postprandial times compared with the control diet. The reductions in arterial blood GIP levels at most postprandial times were of a similar magnitude to those observed in the portal blood. Significant reductions $(P<0.05)$ in arterial blood levels of glucose and insulin were also found after feeding the pigs on the diet containing the lowest concentration of guar gum $(20 \mathrm{~g} / \mathrm{kg})$, but only in the early postprandial phase $(\leqslant 60 \mathrm{~min})$. No reductions in GIP levels in arterial blood were found after the $20 \mathrm{~g} / \mathrm{kg}$ diet in the first 30 min postprandial phase, but some significant reductions $(P<0.05)$ were observed at later postprandial times. 


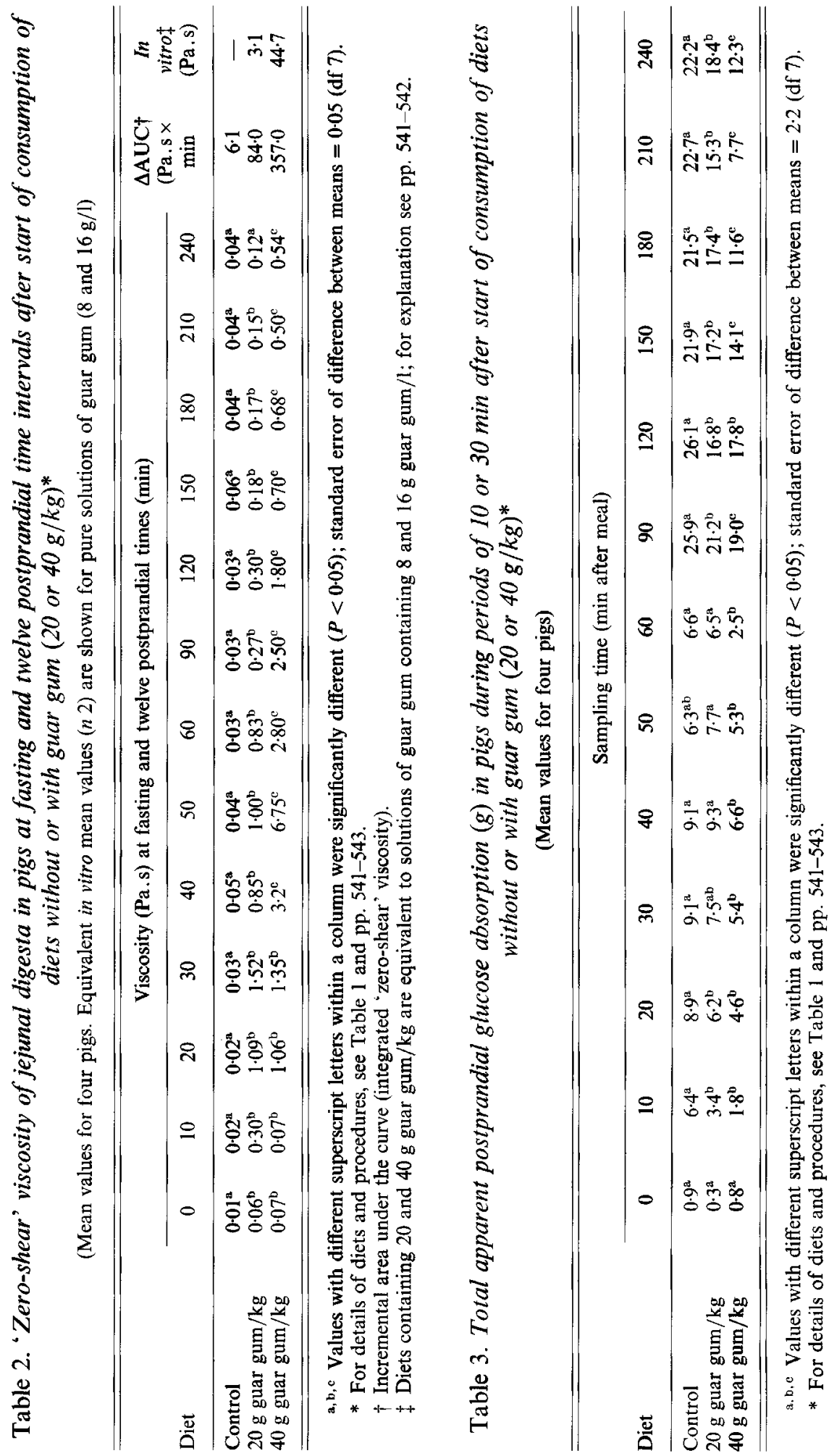




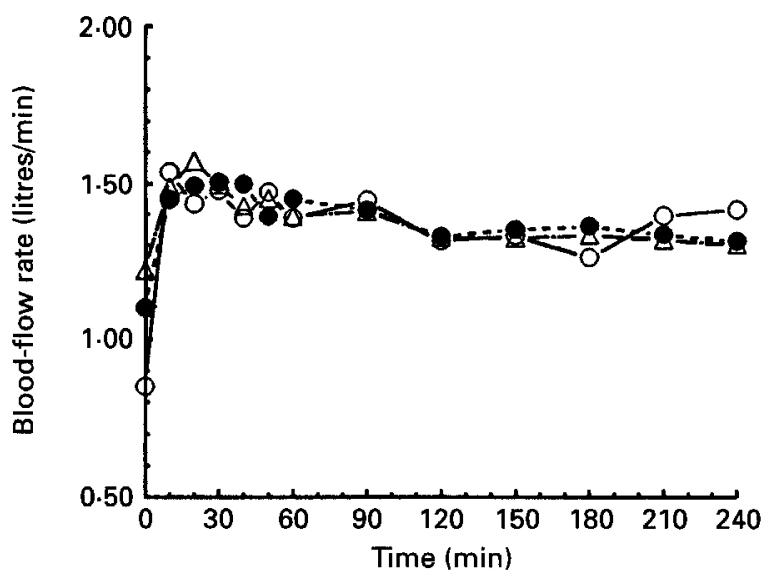

Fig. 2. Effect of guar-gum supplementation on blood-flow rate (litres $/ \mathrm{min}$ ) in the hepatic portal vein in growing pigs; (O) control semi-purified (SP) diet; (O) SP diet supplemented with $20 \mathrm{~g}$ guar gum $/ \mathrm{kg} ;(\triangle) \mathrm{SP}$ diet supplemented with $40 \mathrm{~g}$ guar gum $/ \mathrm{kg}$. Values are means for four pigs. For details of composition of SP diet see Table 1.

Net apparent postprandial glucose absorption, insulin and GIP secretion

Net apparent glucose absorption, and insulin and GIP secretion rates were determined over the $4 \mathrm{~h}$ postprandial period on the basis of the veno-arterial differences and instantaneous blood-flow rate measured in the hepatic portal vein (Rérat et al. 1980). Results showing total apparent glucose absorption and hormone production in response to control and guar-gum diets are presented in Tables 3, 4 and 5. Diets containing guar gum (at both concentrations) significantly reduced $(P<0 \cdot 05)$ the rate of glucose absorption. The $20 \mathrm{~g} / \mathrm{kg}$ guar-gum diet suppressed cumulative glucose absorption to approximately 87 and $78 \%$ of the control values during the $1 \mathrm{~h}$ and $4 \mathrm{~h}$ postprandial phases respectively. The $40 \mathrm{~g} / \mathrm{kg}$ guar-gum diet reduced postprandial glucose absorption still further, to about 56 and $58 \%$ of the control value during the $1 \mathrm{~h}$ and $4 \mathrm{~h}$ periods respectively. Apparent net insulin production was significantly reduced $(P<0.05)$ after the guar-gum diets, although this effect, which was much less than that seen for glucose absorption, appeared to be biphasic (early and late postprandial periods). Thus, the 20 and $40 \mathrm{~g} / \mathrm{kg}$ guar-gum diets reduced insulin production to approximately 87 and $89 \%$ of the control value respectively, over the $4 \mathrm{~h}$ postprandial period. Significant reductions $(P<0 \cdot 05)$ in apparent GIP production were also observed following the guar-containing diets. These reductions were significantly more pronounced than those seen for insulin production and were similar to the percentage changes seen for glucose absorption. Thus, both the 20 and $40 \mathrm{~g} / \mathrm{kg}$ guar-gum diets attenuated GIP production to about $53 \%$ of the control value during the $4 \mathrm{~h}$ period.

Correlation analysis between net apparent glucose absorption and concentration of guar gum in diet or 'zero-shear' viscosity

Correlation analysis was performed on mean values of glucose absorption during $30 \mathrm{~min}$ and 4 h periods (Table 3) using $Q$ values of equation (3) on p. 543 and 'zero-shear' viscosity values at $30 \mathrm{~min}$ periods and integrated values over $4 \mathrm{~h}$ (Table 2). Integrated $4 \mathrm{~h}$ values were calculated from areas under the viscosity curve (Fig. 1).

A strong correlation was found between the amount of glucose absorbed during a $4 \mathrm{~h}$ period and the concentration of guar gum in the pig diet $\left(r^{2} 0.999, P<0.02\right.$, df 1$)$, indicating a close negative linear relationship between these two variables (Fig. 4(a)). However, correlation analysis did not indicate a close linear relationship between glucose absorption and 'zero-shear' viscosity ( $r^{2} 0 \cdot 898$, not significant, df 1 ; Fig. 4(b)). A much 

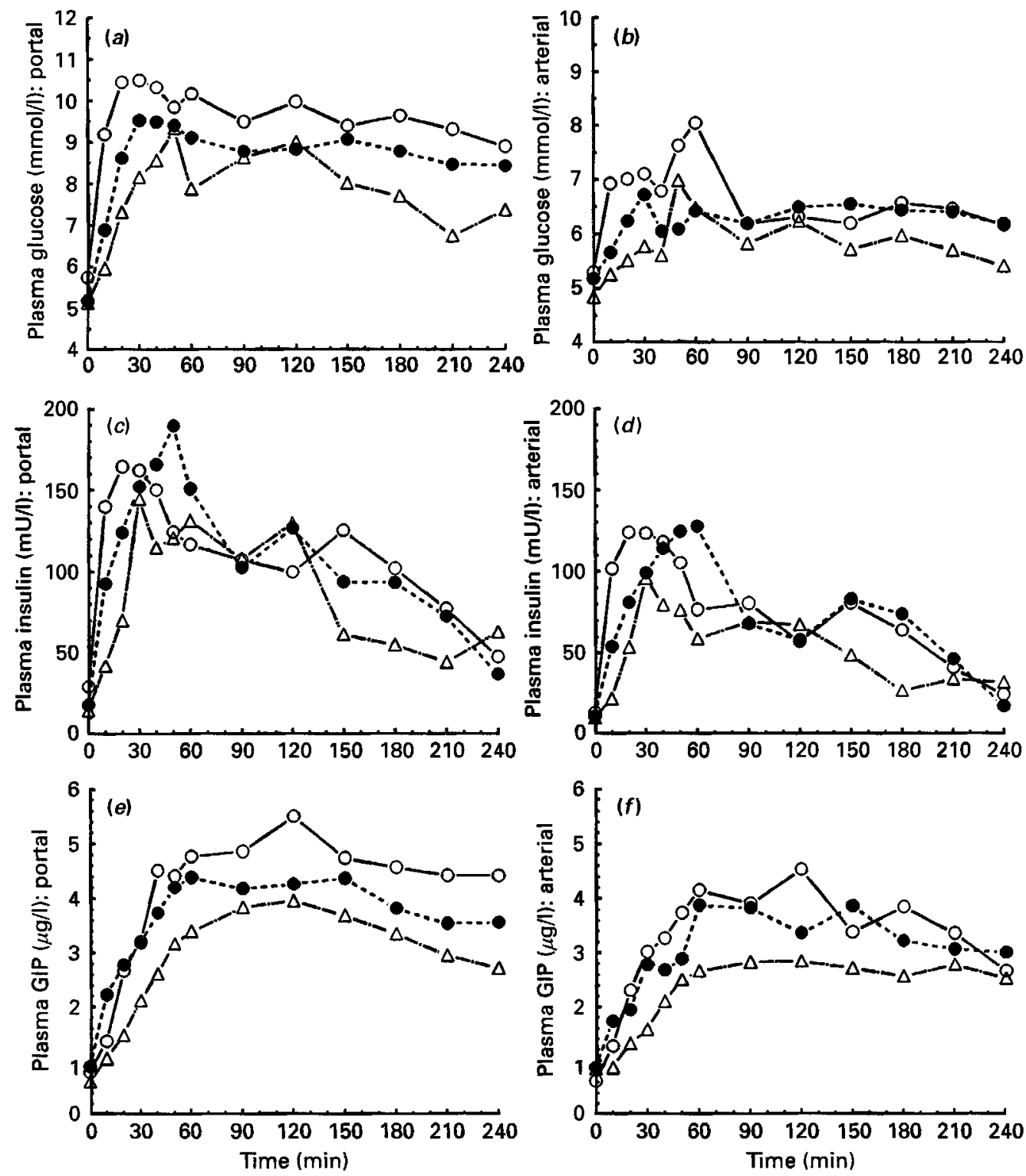

Fig. 3. Effect of guar-gum supplementation on plasma glucose concentrations (mmol/l) in (a) the hepatic portal vein (SED 0.3, df 7) and (b) the mesenteric artery (SED 0.2, df 7); plasma insulin concentrations (mU/l) in (c) the hepatic portal vein (SED 8.5, df 7) and (d) the mesenteric artery (SED 7.0, df 7); and plasma gastric inhibitory polypeptide (GIP) concentrations $(\mu \mathrm{g} / \mathrm{l})$ in (e) the hepatic portal vein (SED 0.22, df 7 ) and (f) the mesenteric artery (SED 0.175, df 7), in growing pigs; (O) control semi-purified (SP) diet; (O) SP diet supplemented with $20 \mathrm{~g}$ guar

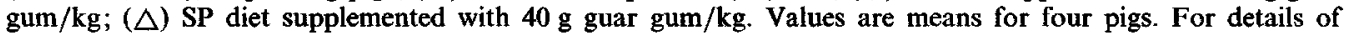
composition of SP diet see Table 1.

closer relationship between these variables was indicated when a non-linear model was applied (e.g. $r^{2} 0.948$ for a power law fit). Indeed, a similar relationship was found when the same non-linear analysis was performed on glucose absorption and viscosity data taken at $30 \mathrm{~min}$ intervals rather than over $4 \mathrm{~h}\left(r^{2} 0 \cdot 349\right.$, df 22). Linear analysis of the same data produced an $r^{2}$ of only 0.098 (df 22). 


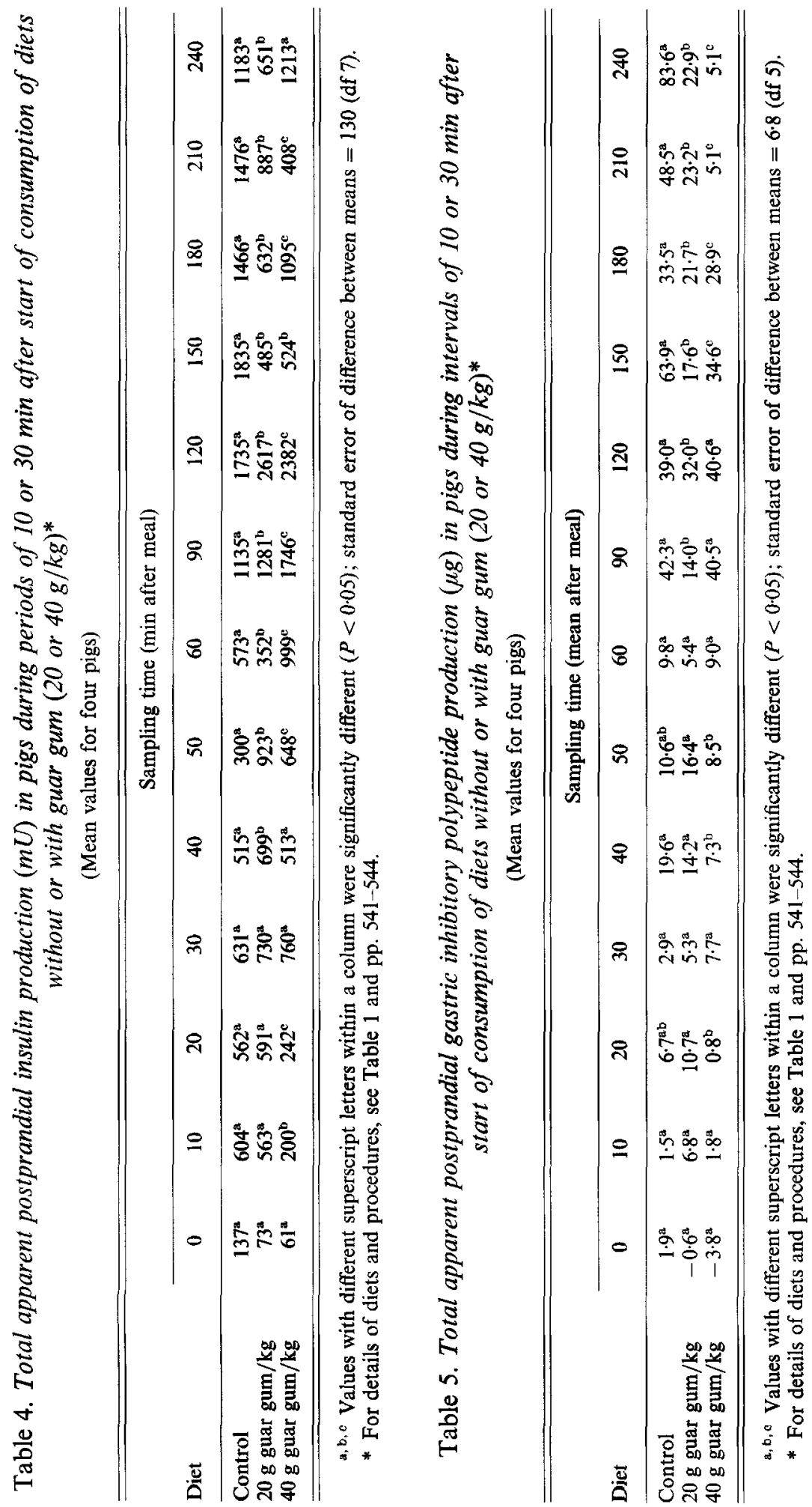



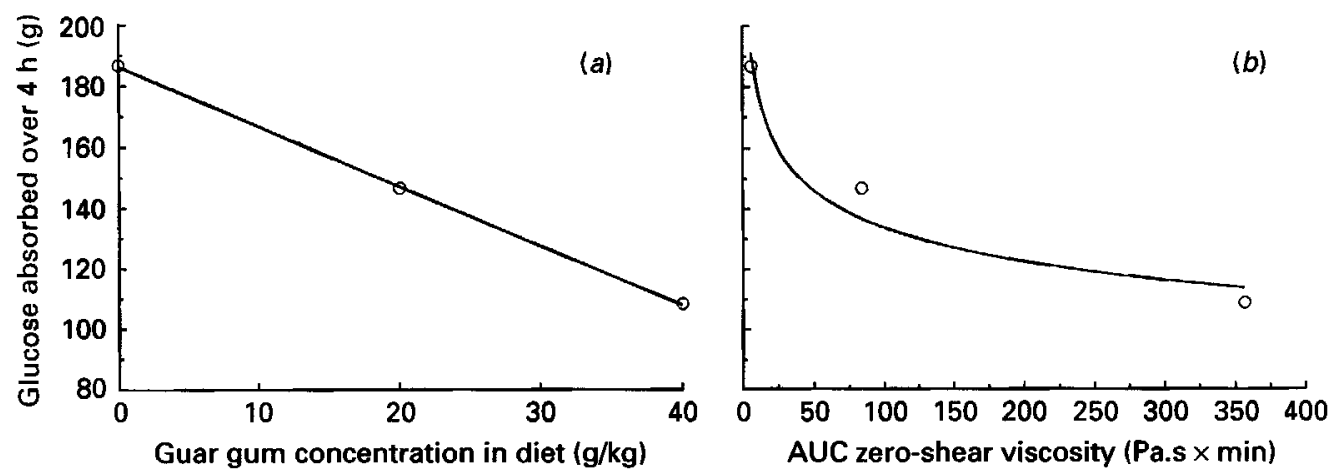

Fig. 4. (a) Glucose absorbed over $4 \mathrm{~h} \mathrm{(g)} v$. guar gum concentration $(\mathrm{g} / \mathrm{kg}$ ) in a semi-purified diet fed to growing pigs. Experimental points are mean values ( $n 8$ observations). Correlation analysis of linear model, $r^{2} 0.999$, $\boldsymbol{P}<0.02$, df 1). (b) Glucose absorbed over $4 \mathrm{~h} \boldsymbol{v}$. area under the curve (AUC) 'zero-shear' viscosity ( $\mathrm{mPa} . \mathrm{s} \times \mathrm{min}$ ) of digesta of pigs after consumption of diets with or without guar gum (20 or $40 \mathrm{~g} / \mathrm{kg}$ ). Values are means for four pigs. Correlation analysis of non-linear model (power law), $r^{2} 0.948$, df 1 . For details of composition of diet see Table 1 .

\section{DISCUSSION \\ 'Zero-shear' viscosity}

The results of the present study clearly show that the liquid SP diets containing guar gum, when fed to conscious growing pigs, produced substantial increases in digesta viscosity in the mid-jejunum over a $4 \mathrm{~h}$ postprandial period (Fig. 1; Table 2), an effect that was strongly dependent on the concentration of guar gum in the original diet. Thus, diets containing 20 and $40 \mathrm{~g}$ guar gum $/ \mathrm{kg}$ produced 14- and 60-fold increases in integrated viscosity levels respectively, relative to the viscosity level produced after the control diet (Table 2). Measurements of 'zero-shear' viscosity were made on the whole jejunal digesta and no assessment was made, therefore, of the effects of insoluble particulate material on the rheological behaviour of guar gum in the digesta samples. Recent work in our laboratory has shown that this is of considerable importance when interpreting, for example, the contribution made by guar galactomannan to the viscosity of complex biopolymer mixtures, such as those found in human and pig digesta (Rayment et al. 1994). Such studies are of crucial importance if we are to understand more precisely the mechanism of action of guar gum and other s-NSP in the gastrointestinal tract.

The 'zero-shear' viscosity profiles (Fig. 1) of control and guar-containing digesta seen in the present pig study were similar to those observed in our earlier studies (Roberts et al. $1990 a, b)$, in which pigs were fitted with re-entrant rather than T-piece cannulas. Thus, it would seem that reliable results can be obtained from using the simple T-piece cannula, even though the re-entrant cannula is a more useful preparation in that it allows total digesta collection and ensures, therefore, that the measurements of digesta viscosity are more representative of results in the mid-jejunum.

Although both concentrations of guar gum in the pigs' diet (20 and $40 \mathrm{~g} / \mathrm{kg}$ ) generated large increases in digesta viscosity, the differences in viscosity between these two concentrations were small when compared with the in vitro measurements of viscosity of the guar-gum solutions added to the original diet (Table 2). A possible explanation for this is that there are substantial differences in total volume of digesta passing through the jejunum as a result of changes in the flux of endogenous secretions and/or fluid absorption in the gut (Roberts et al. $1990 \mathrm{a}, \mathrm{b}$; Roberts, 1991). Thus, the $40 \mathrm{~g} / \mathrm{kg}$ guar-gum diet appeared to be diluted by the presence of additional fluid in the digesta. This is also thought to be part 
of the explanation for recent observations in pigs showing small differences in 'zero-shear' viscosity between digesta samples containing low- and high- $\mathrm{M}_{\mathrm{w}}$ guar gum (Roberts et al. 1990 a). Changes in the rate of gut secretions are not unique to meals containing s-NSP; variations in the amount and content of pancreatic secretions in response to cereal-based meals have been reported in earlier studies in pigs (Zebrowska \& Low, 1987).

\section{Plasma glucose, insulin and gastric inhibitory polypeptide concentrations}

Postprandial glucose concentrations in both portal and arterial blood were significantly reduced by the guar-containing diets (Fig. 3(a) and (b)). The greatest reductions were seen in the early postprandial phase. The reductions in arterial blood glucose levels in pigs given the highest concentration of guar gum $(40 \mathrm{~g} / \mathrm{kg})$ are consistent with the glucose-lowering effects seen in earlier studies in which pigs were given similar concentrations of guar gum (Sambrook \& Rainbird, 1985; Malmlöf et al. 1989). In our present study the glucoselowering effect of guar gum was more marked in the portal vein than in the mesenteric artery, a finding that confirms earlier observations by Malmlöf et al. (1989). No comparable results are available from human studies, however, since for obvious practical and ethical reasons measurements of glucose concentrations in the portal blood are difficult to obtain.

It is well known that fasting and postprandial blood glucose concentrations vary according to site of sampling (i.e. vein, artery, capillary) and this is clearly an important factor when interpreting an individual's glycaemic response to a meal (Burrin \& Alberti, 1990). Moreover, measurements of glucose concentrations in the peripheral venous blood over a stipulated time period are unlikely to give a reliable indication of the rate of glucose absorption. Accordingly, in some studies of healthy human subjects guar-containing meals have been shown to have negligible effects on postprandial hyperglycaemia, whilst at the same time significantly reducing plasma insulin and GIP levels (Morgan et al. 1985; Ellis et al. 1988, 1991). These results are based on measurements taken from the peripheral blood alone, which represent the net effect of a number of post-absorptive processes. In such studies, changes in plasma GIP levels in peripheral venous blood may provide a more reliable indicator of the rate of glucose absorption, as indicated in the present study (see p. 553).

Reductions in arterial and portal plasma insulin levels were seen after the $40 \mathrm{~g} / \mathrm{kg}$ guargum diet, mainly in the early and late postprandial periods, whereas reductions were seen after the $20 \mathrm{~g} / \mathrm{kg}$ guar-gum diet in the early phase only. This insulin-reducing effect, which was less marked than the hypoglycaemic effect of guar gum, is, nevertheless, similar to that reported in earlier pig studies (Sambrook \& Rainbird, 1985; Malmlöf et al. 1989) using guar-containing diets. Recent studies in humans (Morgan et al. 1985; Ellis et al. 1991) have demonstrated similar insulin-sparing effects in subjects given guar-containing meals. However, Ellis et al. (1991) have shown that the insulin-sparing effect of guar gum is negligible in healthy subjects who produce a small insulin response postprandially.

A substantial proportion of the total insulin secreted from the pancreas is 'lost' during the first passage through the liver via hepatic extraction. Thus, concentrations of insulin in the peripheral blood will be much lower than in the portal blood, as seen in the present study (Fig. 3(c) and (d)) and in a similar study by Malmlöf et al. (1989). However, although postprandial insulin concentrations in the portal blood were higher than in the arterial blood, the insulin-lowering effect of guar gum was found to be only slightly greater in the former than in the latter (Fig. 3(c) and (d)). In agreement with a previous study in pigs (Sambrook \& Rainbird, 1985), guar gum also significantly delayed the time taken to reach a peak insulin concentration. This delay, and the reduction in the rise of plasma insulin in response to the guar-gum diet, is assumed to be due to a slower rate of glucose absorption 
from the small intestine. However, glucose absorption is not the only factor determining postprandial insulin concentrations. It is known that the stimulation of the entero-insular axis, a notable component of which is the insulinotrophic hormone GIP, also has an important role to play (Morgan et al. 1979, 1985). The addition of guar gum to the diet of growing pigs significantly reduced postprandial GIP concentrations in portal and arterial blood by about the same degree as the reductions in plasma glucose levels, consistent with a role for GIP in the control of insulin secretion (Fig. 3(e) and (f)). The importance of GIP in mediating the glycaemic response has also been shown recently in piglets (Ponter et al. 1991), and these results are similar to those in earlier studies in human subjects (Morgan et al. 1979, 1985).

\section{Blood-flow rate}

An indication of the rate and extent of digestion and absorption of starchy foods can be obtained from measurements of the changes in blood glucose concentrations. To obtain quantitative measurements of glucose absorption and hormone production, however, it is necessary to monitor the flow rate of blood in the hepatic portal vein. Methods to determine blood-flow rate, which have been routinely available for use in pigs to date include isotope dilution (Braude et al. 1970), indicator dilution (Anderson, 1974), thermal dilution (White et al. 1974) and the electromagnetic probe which is attached as a cuff around the blood vessel (Rérat et al. 1977, 1979, 1980; Giusi-Perier et al. 1989). Although the latter method appears to be both sensitive and accurate, it only allows reliable measurements to be made for 2-4 weeks after surgery. The general principle of employing a 'cuff' surrounding the vessel to measure blood-flow rates instantaneously was employed in the present study, but an ultrasonic flow probe was selected for testing rather than the electromagnetic preparation.

In the current study the surgically-modified animals remained viable for 6 weeks enabling repeated measurements of blood-flow rates within the same animal; this period compares favourably with that of $18 \mathrm{~d}$ quoted by Rérat et al. (1980) who used an electromagnetic flow probe. Mean blood-flow rate following each meal (pooled values for all animals) was 1.36 litres $/ \mathrm{min}$ or $38.8 \mathrm{ml} / \mathrm{min}$ per $\mathrm{kg}$ live weight (Fig. 2). This compares closely with a value of $37.4 \mathrm{ml} / \mathrm{min}$ per $\mathrm{kg}$ live weight recorded by Rérat et al. (1988). In both the present study and the earlier studies of nutrient absorption (Rérat et al. 1988) there was no correlation between mean blood-flow rate and the composition of the meal ingested; blood flow seems to be more dependent on the behaviour of the animal on the day of sampling. This point has been reiterated in the most recent study by Simões Nunes \& Malmlöf (1992). Following an initial rise at the onset of feeding, mean blood-flow rate remained steady throughout the postprandial sampling period. In this present study the animals were generally quiescent and recumbent. However, clinical studies in man (Brown et al. 1989) have shown that the blood-flow rate is significantly reduced when an individual moves from an upright to a supine position. Thus, postural effects need to be taken into account when extrapolating results from pigs to humans, particularly when accurate measurements of portal blood flow are required for quantitative studies of nutrient absorption.

\section{Net apparent glucose absorption and insulin and gastric inhibitory polypeptide production}

Combined measurement of veno-arterial differences with blood-flow rates in the hepatic portal vein enabled the calculation of net apparent glucose absorption and production of insulin and GIP. Diets containing guar gum (at both concentrations) reduced significantly the amount of glucose absorbed postprandially relative to the control (Table 3 ). Thus, in pigs fed on diets containing guar gum at concentrations of 20 and $40 \mathrm{~g} / \mathrm{kg}$, there were reductions of about 22 and $42 \%$ respectively in the amount of glucose absorbed over a $4 \mathrm{~h}$ 
period. These results, in addition to similar findings recently reported by Simões Nunes \& Malmlöf (1992), provide the first direct evidence, albeit in an experimental animal, that guar gum added to starch-rich diets reduces the rate of glucose absorption from the small intestine. The glucose absorption data presented in the present paper should only be regarded as 'apparent absorption' because the technique provides no estimation of the amount of glucose immediately metabolized by the mucosa of the small intestine. It is possible, also, that a proportion of dietary starch, and/or hydrolysed products of starch, remains unabsorbed in the small intestine in the presence of guar gum, thus providing a potential substrate for microbial enzymes in the large intestine. Early human studies (Jenkins et al. (1978) have provided little evidence of this, although recent studies in pigs using various sources of NSP have demonstrated decreased glucose absorption over a $24 \mathrm{~h}$ period leading to an increase in the proportion of the available carbohydrate reaching the large intestine for subsequent fermentation (Giusi-Perier et al. 1989). A useful future experiment would be, therefore, to quantify the production of short-chain fatty acids (e.g. butyrate) using the same technique employed in the present study, based on the assumption that the portal blood is the main route of absorption for these colonic metabolites. It would also be useful to extend the sampling period over which glucose absorption can be measured to account for all the wheat starch fed to the pigs.

In view of the effect of guar gum on glucose absorption seen in the current study, the reduction in apparent insulin production following each of the guar-gum meals is not unexpected (Table 4). However, the magnitudes of these reductions over $4 \mathrm{~h}$, about $11-13 \%$ of that produced after the control, were smaller than we would have expected from the glucose-reducing effect of guar gum. Moreover, the results of a recent pig study have shown that a diet containing guar gum at a concentration of $60 \mathrm{~g} / \mathrm{kg}$ reduces insulin production by as much as $30 \%$ of that produced for the control over a $8 \mathrm{~h}$ postprandial period (Simões Nunes \& Malmlöf, 1992). In the present study the insulin-reducing effect of guar gum appeared to be biphasic (i.e. early and late phases of the postprandial curve), so that in the last $2 \mathrm{~h}$ of the postprandial period guar gum reduced insulin production by between 45 and $55 \%$ of the control value.

Diets containing guar gum also reduced apparent production of GIP (Table 5) by about the same proportion seen for the reduction of glucose absorption after the $40 \mathrm{~g} / \mathrm{kg}$ guargum meal (Table 3). Moreover, the reductions in glucose absorption at different postprandial times followed more closely the reductions in GIP production than the corresponding insulin values. Thus, correlation analysis of values in the first $60 \mathrm{~min}$ postprandial period showed a stronger linear relationship between glucose absorption and GIP production (Spearman rank correlation $r^{2} 0.302, P<0.01$, df 20) than between glucose absorption and insulin production (Spearman rank correlation $r^{2} 0.232, P<0.05$, df 20 ). The closer relationship between GIP production and glucose absorption is perhaps indicative of the steady secretion of GIP, the release of which is directly stimulated by the rate of absorption of glucose in the small intestine. In contrast, the secretion of insulin in response to glucose absorption and stimulation of the entero-insular axis is pulsatile and biphasic (Matthews et al. 1983), a pattern of release that is unlikely to correlate closely with the rate of glucose absorption.

\section{Relationship between glucose absorption and digesta viscosity}

Correlation analysis revealed an inverse linear relationship between glucose absorption during the $4 \mathrm{~h}$ postprandial period and the concentration of guar gum in the original pig diet (Fig. 4(a)). However, the same analysis did not indicate a similar relationship between glucose absorption and 'zero-shear' viscosity of jejunal digesta. A stronger relationship between glucose absorption and average viscosity levels, either during intervals of $30 \mathrm{~min}$ 
or during the whole $4 \mathrm{~h}$ period (i.e. area under the curve), was indicated when a non-linear model was applied (Fig. 4(b)). Although at this stage there are insufficient data to attempt to utilize either of these models for predictive purposes, the results do provide the first direct evidence of the importance of viscosity in determining the physiological activity of guar gum. If an inverse, non-linear relationship between glucose absorption and digesta viscosity proves to be an appropriate model, then this would indicate that reductions in glucose absorption are proportionately greater at low levels of viscosity than at high levels.

\section{Conclusions}

We have demonstrated that a liquid SP diet containing high- $\mathbf{M}_{w}$ guar gum increased digesta viscosity significantly in the mid-jejunum and reduced the rate of glucose absorption and apparent insulin and GIP production in growing pigs. The rate of glucose absorption after a meal was found to be inversely related to the 'zero-shear' viscosity of digesta in the small intestine. The modification of the entero-insular axis is strongly implicated in the mechanism of action by which guar gum improves glycaemic control. An ultrasonic bloodflow probe, a novel technique for measuring blood-flow rates instantaneously, was used successfully to quantify glucose absorption and hormone secretion far more directly than is possible at present with human subjects. This again serves to highlight the benefits and the suitability of using the pig as an animal model for studies of this nature (Leeds et al. 1980; Miller \& Ullrey, 1987).

The authors acknowledge the financial support of the Biotechnology and Biological Sciences Research Council. Drs J. W. Sissons and I. E. Sambrook provided much practical help and advice throughout this study. Expert technical assistance was provided by Mrs C. Jones and Mr S. Young and our thanks go to Mr H. A. Smith for his assistance during sampling and his considerable help during the subsequent analyses. We are grateful also to Professors E. R. Morris and S. B. Ross-Murphy for their help and advice with the rheological aspects of this study.

\section{REFERENCES}

Anderson, D. M. (1974). The measurement of portal and hepatic blood flow in pigs. Proceedings of the Nutrition Society 33, 30A.

Barnes, R. J., Comline, R. S., Dobson, A. \& Prost, C. J. (1983). An implantable transit-time ultrasonic blood flow meter. Journal of Physiology 345, 2P-3P.

Blackburn, N. A., Redfern, J. S., Jarjis, H., Holgate, A. M., Hanning, I., Scarpello, J. H. B., Johnson, I. T. \& Read, N. W. (1984). The mechanism of action of guar gum in improving glucose tolerance in man. Clinical Science 66, 329-336.

Braude, R., Cutts, I. R., Myres, A. W. \& Porter, J. W. G. (1970). Measurement of amino acid levels in portal blood plasma of pigs and rate of portal blood flow. Proceedings of the Nutrition Society 29, 60A.

Brown, H. S., Halliwell, M., Qamar, M., Read, A. E., Evans, J. M. \& Wells, P. N. T. (1989). Measurement of normal portal venous blood flow by Doppler ultrasound. Gut 30, 503-509.

Burrin, J. M. \& Alberti, K. G. M. M. (1990). What is blood glucose: can it be measured? Diabetic Medicine 7, $199-206$.

Edwards, C. A., Johnson, I. T. \& Read, N. W. (1988). Do viscous polysaccharides slow absorption by inhibiting diffusion or convection? European Journal of Clinical Nutrition 42, 307-312.

Edwards, C. A. \& Read, N. W. (1990). Fibre and small intestinal function. In Dietary Fibre Perspectives 2, pp. 52-75 [A. R. Leeds, editor]. London: John Libbey.

Ellis, P. R., Apling, E. C., Leeds, A. R. \& Bolster, N. R. (1981). Guar bread: acceptability and efficacy combined. Studies on blood glucose, serum insulin and satiety in normal subjects. British Journal of Nutrition 46, 267-276.

Ellis, P. R., Dawoud, F. M. \& Morris, E. R. (1991). Blood glucose, plasma insulin and sensory responses to guarcontaining wheat breads: effect of molecular weight and particle size of guar gum. British Journal of Nutrition 66, 363-379.

Ellis, P. R., Kamalanathan, T., Dawoud, F. M., Strange, R. N. \& Coultate, T. P. (1988). Evaluation of guar biscuits for use in the management of diabetes: tests of physiological effects and palatability in non-diabetic volunteers. European Journal of Clinical Nutrition 42, 425-435. 
Ellis, P. R. \& Morris, E. R. (1991). Importance of the rate of hydration of pharmaceutical preparations of guar gum: a new in vitro monitoring method. Diabetic Medicine 8, 378-381.

Ellis, P. R., Morris, E. R. \& Low, A. G. (1986). Guar gum: the importance of reporting data on its physicochemical properties. Diabetic Medicine 3, 490-491.

Gatenby, S. J., Ellis, P. R., Morgan, L. M., Dawoud, F. M. \& Judd, P. A. (1991). The effect of low, medium and high molecular weight grades of guar gum on postprandial blood glucose and plasma insulin in non-insulindependent diabetics. Proceedings of the Nutrition Society 50, 58A.

Giusi-Perier, A., Fiszlewicz, M. \& Rérat, A. (1989). Influence of diet composition on intestinal volatile fatty acid and nutrient absorption in unanaesthetised pigs. Journal of Animal Science 67, 380-402.

Jarjis, H. A., Blackburn, N. A., Redfern, J. S. \& Read, N. W. (1984). The effect of ispaghula (Fybogel and Metamucil) and guar gum on glucose tolerance in man. British Journal of Nutrition 51, 371-378.

Jenkins, D. J. A., Wolever, T. M. S., Leeds, A. R., Gassull, M. A., Haisman, P., Dilawari, J., Goff, D. V., Metz, G. L. \& Alberti, K. G. M. M. (1978). Dietary fibre, fibre analogues and glucose tolerance; importance of viscosity. British Medical Journal i, 1353-1354.

Leeds, A. R., Kang, S. S., Low, A. G. \& Sambrook, I. E. (1980). The pig as a model for studies on the mode of action of guar gum in normal and diabetic man. Proceedings of the Nutrition Society 39, 44A.

Macagno, E. O., Christensen, J. \& Lee, C. L. (1982). Modelling the effect of wall movement on absorption in the intestine. American Journal of Physiology 243, G541-G550.

Malmlöf, K., Simões Nunes, C. \& Askbrant, S. (1989). Effect of guar gum on plasma urea, insulin and glucose in the growing pig. British Journal of Nutrition 61, 67-73.

Matthews, D. R., Lang, D. A., Burnett, M. A. \& Turner, R. C. (1983). Control of pulsatile insulin secretion in man. Diabetologia 24, 231-237.

Miller E. R. \& Ullrey, D. E. (1987). The pig as a model for human nutrition. Annual Reviews in Nutrition 7 , 361-382.

Morgan, L. M., Flatt, P. R. \& Marks, V. (1988). Nutrient regulation of the entero-insular axis and insulin secretion. Nutrition Research Reviews 1, 79-97.

Morgan, L. M., Goulder, T. J., Tsiolakis, D., Marks, V. \& Alberti, K. G. M. M. (1979). The effect of unabsorbable carbohydrate on gut hormones: modification of post-prandial GIP secretion by guar. Diabetologia 17, 85-89.

Morgan, L. M., Tredger, J. A., Madden, A., Kwasowski, P. \& Marks, V. (1985). The effect of guar gum on carbohydrate, fat and protein stimulated gut hormone secretion: modification of postprandial gastric inhibitory polypeptide and gastrin responses. British Journal of Nutrition 53, 467-475.

Morris, E. R. (1990). Shear-thinning of 'random coil' polysaccharides: characterisation by two parameters by a simple linear plot. Carbohydrate Polymers 13, 85-96.

Peterson, D. B., Ellis, P. R., Baylis, J. M., Fielden, P., Ajodhia, J., Leeds, A. R. \& Jepson, E. M. (1987). Low dose guar in a novel food product: improved metabolic control in non-insulin dependent diabetes. Diabetic Medicine 4, 111-115.

Ponter, A. A., Seve, B., Cortamira, N. O., Salter, D. N. \& Morgan, L. M. (1991). The effects of dietary energy source and tryptophan on hormones of the entero-insular axis and glucose in the early weaned pig after an intragastric infusion of glucose. Proceedings of the Nutrition Society 50, 227A.

Rainbird, A. L. (1983). Studies on the physiological action of dietary fibre in the stomach and small intestine of growing pigs. PhD Thesis, University of Reading.

Rainbird, A. L., Low, A. G. \& Zebrowska, T. (1984). Effect of guar gum on glucose and water absorption from isolated loops of jejunum in conscious growing pigs. British Journal of Nutrition 52, 489-498.

Rayment, P., Ross-Murphy, S. B. \& Ellis, P. R. (1994). Rheology of guar galactomannan/rice starch mixtures. Carbohydrate Polymers 25, 227.

Rérat, A., Aumaitre, A., Vaissade, P. \& Vaugelade, P. (1977). Experimental qualitative study of sugar absorption after consumption of a lactose-based diet in the pig. Annales de Biologie Animale, Biochimie, Biophysique 17 , 589-596.

Rérat, A., Vaissade, P. \& Vaugelade, P. (1979). Absorption kinetics of amino acids and reducing sugars during digestion of barley or wheat meals in the pig. Preliminary data. Annales de Biologie Animale, Biochimie, Biophysique 19, 739-747.

Rérat, A., Vaissade, P. \& Vaugelade, P. (1988). Absorption kinetics of dietary hydrolysis products in conscious pigs given diets with different amounts of fish protein. 1. Amino-nitrogen and glucose. British Journal of Nutrition 60, 91-104.

Rérat, A., Vaugelade, P.\& Villiers, P. (1980). A new method for measuring the absorption of nutrients in the pig: critical examination. In Current Concepts of Digestion and Absorption in Pigs, pp. 177-214 [A. G. Low and I. G. Partridge, editors]. Reading: National Institute for Research into Dairying.

Roberts, F. G. (1991). Studies of the physico-chemical characteristics and physiological activity of guar gum, a soluble fibre source, using the pig as an animal model for man. PhD Thesis, University of London.

Roberts, F. G., Smith, H. A., Low, A. G. \& Ellis, P. R. (1990a). Influence of wheat breads containing guar flour supplements of high and low molecular weights on viscosity of jejunal digesta in the pig. In Dietary Fibre: Chemical and Biological Aspects, pp. 164-168 [D. A. T. Southgate, K. Waldren, I. T. Johnson and G. R. Fenwick, editors]. Cambridge: The Royal Society of Chemistry.

Roberts, F. G., Smith, H. A., Low, A. G., Ellis, P. R., Morris. E. R. \& Sambrook, 1. E. (1990 b). Influence of guar 
gum flour of different molecular weights on viscosity of jejunal digesta in the pig. Proceedings of the Nutrition Society 49, 53A.

Robinson, G., Ross-Murphy, S. B. \& Morris, E. R. (1982). Viscosity-molecular weight relationships, intrinsic chain flexibility and dynamic solution properties of guar galactomannan. Carbohydrate Research 107, 17-32.

Sambrook, I. E. \& Rainbird, A. L. (1985). The effect of guar gum and level and source of dietary fat on glucose tolerance in growing pigs. British Journal of Nutrition 54, 27-35.

Simões Nunes, C. \& Malmlöf, K. (1992). Effects of guar gum and cellulose on glucose absorption, hormonal release and hepatic metabolism in the pig. British Journal of Nutrition 68, 693-700.

White, F., Webster, A. J. F., Farrell, D. J. \& Jones, A. S. (1974). Measurement of portal blood flow in the pig by the continuous thermal dilution technique. Proceedings of the Nutrition Society 33, 31A-32A.

Zebrowska, T. \& Low, A. G. (1987). The influence of diets based on whole wheat, wheat flour and wheat bran on exocrine pancreatic secretion in pigs. Journal of Nutrition 117, 1212-1216. 